\title{
Coronaspeak as Key to Coronaculture: Studying New Cultural Practices Through Neologisms
}

\author{
Iryna O. Alyeksyeyeva ${ }^{1}$, Tetyana A. Chaiuk ${ }^{2} \&$ Elizaveta A. Galitska ${ }^{3}$ \\ ${ }^{1}$ Institute of Philology, Taras Shevchenko National University of Kyiv, Kyiv, Ukraine \\ ${ }^{2}$ School of Law, Taras Shevchenko National University of Kyiv, Kyiv, Ukraine \\ ${ }^{3}$ Kyiv Gymnasium \# 86 "Consul", Kyiv, Ukraine \\ Correspondence: Tetyana A. Chaiuk, School of Law, Taras Shevchenko National University of Kyiv, Kyiv, \\ Ukraine. E-mail: chajuk.t@gmail.com
}

Received: August 6, 2020

Accepted: September 8, 2020

Online Published: September 15, 2020

doi:10.5539/ijel.v10n6p202

URL: https://doi.org/10.5539/ijel.v10n6p202

\begin{abstract}
The research explores neologisms that have entered everyday English discourse during the coronavirus pandemic and formed so-called Coronaspeak. The analysis reveals that three approaches to neologisms are applicable to lexemes of Coronaspeak: the stylistic theory that is relevant to the words that used to be scientific terms but have been adopted by non-specialists, the etymological approach that regards as neologisms those new coinages that have developed a new meaning, and the denotational approach where neologisms are the lexemes created to nominate new concepts. Drawing on the assumption that language units verbalise cultural phenomena, the further study of Coronaspeak suggests that the modern English-speaking societies undergo a number of cultural changes: medicalisation of public discourse that originates from the government policy to engage the public in the struggle against COVID-19 as well as from using the pandemic as an argument in ideological and political conflicts; conceptualisation of the pandemic as a milestone, a turning point in history; introduction of new categories for social groups based on such criteria as health, profession, or attitude to the pandemic and socially responsible behaviour (e.g., clinically vulnerable people, key workers, covadults); development of new or modification of old cultural practices that embrace lifestyle (coronacocooing, WFH, drivecation), appearance (corona hair, coronabesity), patterns of online and offline communication (homeference, video party, coronadating, Wuhan shake); reconceptualisation of pre-pandemic concepts (home), and, finally, emergence of new types of interpersonal relations (coronarelationship, corona boyfriend).
\end{abstract}

Keywords: neologism, pandemic, coronavirus, medicalisation, categorisation, cultural practice

\section{Introduction}

The year 2020 has brought the unexpected for the globalised world: the coronavirus pandemic has interrupted the routine of most people, has interfered with their work/study schedules, private life, and has impacted on social norms. Viruses are not a new challenge for humanity. Within the last one hundred years, there have been outbreaks of Spanish Flu (1918-1920), Asian Flu (1957-1958), AIDS (1981-present day), H1N1 Swine Flu (2009-2010), West African Ebola (2014-2016), Zika Virus (2015-present day), Jarus (2020), yet it is COVID-19 that has changed modern policies, economies, societies and seems to be changing cultures. Being formally a health issue, the coronavirus outbreak was declared Public Health Emergency of International Concern in January, 2020 (World Health Organization, 2020), and in March, 2020, its status was changed for 'global pandemic'.

The extraordinary health emergency situation has entailed a number of linguistic challenges. Though medicine is not directly related to linguistics, the actual practice of diagnosis and treatment is essentially language-dependent. Doctor-patient face-to-face communication remains ultimately important despite objective tests upon which modern medicine typically relies (see, for example, Dunaievska \& Chaiuk, 2020; Ha, Anat, \& Longnecker, 2010; Peeters \& Marini, 2018). Alongside medical problems, the case of COVID-19 reveals problems of purely linguistic or communicative nature. Thus, when the virus started to spread in the city of Wuhan and the Chinese government mobilized medical specialists from throughout the country, the doctors encountered language problems in clinical communication with local patients. To cope with the language challenge, the medical 
assistance team of Qilu Hospital of Shandong University compiled The Guidebook of Wuhan Dialect for Medical Assistance Teams, Audio Materials of Wuhan Dialect for Medical Assistance Teams, and The Handbook of Doctor-Patient Communication. The Guidebook included dialect-to-Mandarin translations of 156 words and 76 sentences which are commonly used in diagnosing and treatment (Li, 2020). Later, the Department of Language Information Management of the Chinese Ministry of Education supported compiling The Handbook of Hubei Dialects for Medical Assistance Teams that remarkably facilitated communication between medical assistance teams and patients in Hubei province.

When foreign students and workers started to return to Hubei province, there appeared the need for bilingual handbooks that would inform them of coronavirus and safety measures. To meet the demand, Beijing Advanced Innovation Center for Language Resources of BLCU (Beijing Language and Culture University) compiled $A$ Guide to the Prevention and Control of COVID-19 Epidemic in Foreign Languages. The Guide contains 75 sentences used in daily precautions, entry precautions, medical treatment, and personnel protection in more than 20 languages including Japanese, Korean, Persian, Italian, Arabic, English, German, Russian, and French. The need of linguists' participation in measures taken to handle the disease exacerbated when the outbreak expanded globally and Chinese doctors and virologists began sharing the experience gained in Hubei. As a result, linguists currently emphasise the need for drawing on practical experience, taking advantage of the academic achievements made in applied linguistics, and establishing the discipline of "emergency linguistics" (Li, 2020), a whole new specialization devoted to making language services part of the emergency response to disasters (King's College of London, 2020).

The coronavirus outbreak, however, has impacted on the lives of people who have nothing to do either with linguistic studies or with the medical profession. It has also impacted on societies on the global scale as well as on the level of a household. For example, the disease has been used by political actors on the international arena: Zhao Lijian, a spokesperson of the Chinese Ministry of Foreign Affairs, accused the United States of spreading the coronavirus in Wuhan, the city in Hubei province that became the epicentre of the outbreak (Huang, 2020), while the US President Donald Trump labelled the disease the Chinese virus and "touted" the theory that the coronavirus "originated at the Wuhan Institute of Virology" (Singh, Davidson, \& Borger, 2020).

A number of countries have imposed restrictions on their citizens to reduce face-to-face communication to prevent people from contracting the virus, often involving regulations on the use of facial masks and maintaining social distancing. In some severe cases, governments went so far as to force their citizens to remain at their homes. This lockdown lasted for weeks, for example, in Italy, Spain, Iran, Denmark, Israel, Lebanon and India. As a result, the patterns of everyday life changed: people had to adapt their work styles, household management and communicative practices to the new order. Correspondingly, businesses had to change their ways, too, to meet their clients' new needs and their employees' abilities. The lockdown and the health emergency also influenced the social hierarchy and the perceived status of some social groups.

The external changes had yet to be accommodated by the 'pre-coronavirus' human psyche (in fact, the abbreviation $B C$ has acquired a new meaning, 'before coronavirus', which speaks volumes about how much different the 'post-coronavirus' world has become). Confined in their houses and flats for weeks, either with their family members or alone, people had to reconsider what their family or their solitude meant for them and how their relations should be reshaped or mediated to provide them with the feeling of well-being.

The language readily responds to social changes and new cultural trends. As a rule, the response within the language system takes place in the sphere of vocabulary. It is argued that a frequently used word or expression reflects "the ethos, mood or preoccupations of the passing year" and has "lasting potential as a term of cultural significance" (Oxford Languages, 2019). This presumption enables the Oxford University to announce a word of the year. It is yet to see what word will be granted the status of the most significant among adult English speakers in 2020, but the Oxford Children's Dictionaries \& Language Data team at Oxford University Press having analysed stories submitted by more than 134,000 children for a writing competition has already identified the Children's Word of 2020: coronavirus (Oxford Owl, 2020).

The article aims at analysing those sets of neologisms that have appeared in everyday discourse due to the COVID-19 outbreak and to relate them to the social and cultural processes set in motion by the pandemic.

\section{Literature Review}

The consequences of the coronavirus outbreak have attracted attention of scholars from different scientific fields. Since coping with the pandemic requires changing everyday habits and behaviours, specialists in social and behavioural sciences apply the notion of social norms to the current situation and suggest ways to align human behaviour with health experts' recommendations (Goldberg et al., 2020; Van Bavel et al., 2020). 
New regulations entail a new lifestyle that in its turn brings about new consumer needs and new strategies to market goods. Thus, marketing specialists develop new strategies and analyse companies' adaptive moves (Murphy, Naert, \& Strong, 2020). There are also attempts to approach the current situation as a complex, multi-faceted phenomenon, an amalgam of political, economic, medical, social and cultural issues (see, for example, Blommaert, 2020; Figus, 2020).

Since no social phenomenon can avoid being represented in language, the pandemic has impacted on the language system, language use and discursive practices. One of the earliest linguistic studies addressed COVID-related discourse using approaches that range from corpus-based to content analysis studies. The research offers an insight into a diversity of language aspects: at the macro level, the authors examine institutional discourse of the Malaysian and British governments; at the micro level, the research adopts lexical and semantic foci to study personal posts on virus-related issues (Kim et al., 2020).

The impact of the outbreak on the English language is studied by British linguist and lexicographer Tony Thorne specializing in slang, jargon and cultural history. According to the researcher, "there's been an enormous amount of new language... Some of the language is newly created, some of it is re-purposed old language" (Thorne, 2020). In his interview, the linguist outlines the stages at which Coronaspeak, i.e., language related to the epidemic, has evolved. Thus, the first stage was marked by "medicalisation of our everyday vocabulary"; during the second stage speakers started to invent their own words to refer to the new reality they watched taking shape; the third stage is bound with the institutional discourse, namely the language the government used to pursue its strategic construction of a new world (ibid.).

The effect of the pandemic on the English language, therefore, lies primarily within the scope of lexicology: conceptualisation of new phenomena requires either new words/expressions or reconsideration of old words/expressions endowed with new meanings. Therefore, the term 'new coinage' (or its synonym 'neologism') is the key one for the study. 'New coinage' is defined here as words or phrases that have just entered the vocabulary as well as those words that have already existed but whose meaning has been transformed (Koltsova, 2017, p. 606).

The other consequence of the pandemic belongs to the sphere of discourse, communication, and culture. Mass media, for example, took the advantage of the situation and honed their reality-constructing skills by strategically using the pandemic to cultivate uncertainty, anxiety, and, in the long run, blatant fear (see, for example, Chaiuk \& Dunaievska, 2020). Besides, the coronavirus pandemic has created new social, economic, and political conditions which have brought about novel trends in corporate and interpersonal communication. The new communicative practices have been addressed in the press (see, for example, Bilefsky \& Yeginsu, 2020; Song, 2020) as well as in scientific publications (see, for example, Szabó, 2020; Harrod, Leonard, \& Negra, 2020).

It is obvious that numerous factors have contributed to a rather significant modification of culture that is yet to be explored and described by scholars of various disciplines. The current research examines the newly emerging vocabulary in the attempt to make visible the cultural changes the society is experiencing.

\section{Theoretical Framework}

\subsection{Ethnolinguistic Approach to Language-Culture Relationship}

The research draws on the key assumption of ethnolinguistics that postulates the correlation between language spoken by a community and the community's culture which embraces both abstract phenomena (e.g., the community's worldview and mental patterns) and material expression (e.g., cultural practices ranging from everyday behaviours to special ceremonies and occasions). From this perspective, language is invaluable for researchers because language units, namely grammatical structures and vocabulary, verbalise mental constructs, mark culture-bound relations between them and explicate culture-specific thinking (see, for example, Farese, 2018; Levisen \& Waters, 2018; Thibodeau \& Boroditsky, 2013; Wierzbicka, 1988; Ye, 2004; Yoon, 2004).

\subsection{Neologisms as Objects of Linguistic Research}

The most widespread definition of neologisms interprets them as new words or expressions in a language. Though the very novelty of a word or phrase seems to be an unambiguous key criterion to identify neologisms (also known as new coinages), it is not really the case. Lexical units combine a number of diverse features and, therefore, there are five main approaches to study neologisms, each of the approaches prioritizing one of the five criteria: stylistic, denotational, structural, etymological, and lexicographic (Rets, 2016).

Within the framework of the stylistic approach, a new coinage is a word whose novelty is marked by its new stylistic usage. The example of a stylistic neologism is scientific terms that start to be used in everyday conversations and stop being perceived as scientific. The denotational theory interprets new coinages as words 
that appear to nominate new objects or phenomena. The structural approach defines neologisms as words of an absolutely new acoustic form and structure. Within the etymological approach, a new coinage is a word of the language that has developed a new meaning. For the lexicographic approach, a neologism is a lexical unit that has not yet been registered in dictionaries.

Only four of these criteria (namely, stylistic, denotational, structural, and etymological ones) may be applied in our research to identify the novel lexical units that have been coined to describe pandemic-related phenomena, since digitalisation has significantly simplified and sped up the process of including new words into online dictionaries, which has undermined the validity of the lexicographic approach. Digitalisation has also invited ordinary users to contribute into online dictionaries, Urban Dictionary being one of them. Founded in 1999, it specialises in slang and contains over seven million definitions. Though its definitions are sometimes presented as "merely jokes" and "fakes" (Urban Dictionary, n.d.), nevertheless the dictionary has been used in several court cases as an authority respectable enough "to define slang terms not found in standard dictionaries".

The material of the study includes neologisms collected with the help of continuous sampling in texts from British governmental websites and pandemic-related publications in online British and American media.

\section{Analysis}

The linguistic 'response' of the society permanently exposed to pandemic-related information and statistics is, on the one hand, adopting the medical terminology and using it freely in everyday interactions. On the other hand, psychological unease afflicted by the authorities' restricting rules and the need to verbalise a new lifestyle 'under the new order' leads to an explosion of slang and colloquialisms.

\subsection{Medicalisation of Everyday Discourse}

A growing number of medical terms have turned into part and parcel of everyday discourse. The stage of “"medicalisation' of everyday language" (Thorne, 2020) first of all familiarized non-specialists with the name of the virus itself. The term coronavirus as well as the abbreviation COVID for coronavirus disease quickly became catchwords.

Besides these nominations, the most frequently used and recognisable neologisms are social distance, self-isolation, shelter-in-place, and shielding that migrated from other sciences and changed their meanings on the way. Then they entered the everyday communication among non-specialists. Social distance, a borrowing from psychology and sociology, used to denote 'how close one is happy to get to members of an outgroup' (ibid.). During the pandemic, social distance is interpreted as a safe physical distance between people ranging from 1.5 to 2 metres.

Self-isolation dates back to the 19th century when it belonged to the sphere of political studies and economics and meant 'isolationist nations'. In 2020, self-isolation came to mean "staying at home" (NHS, 2020).

Shelter-in-place appeared in the 1970s and is related to sheltering from nuclear or terror attacks (Dupont, 2020), while today it is a synonym of shielding and means 'staying at home as much as possible and keeping interactions outside to a minimum' (GOV.UK, 2020b). Along with these, everyday discourse accommodated the medical terms antigen, comorbidity, contact tracing, to flatten the curve, immunocompromised, intubation, pathogen, patient zero, PCR test, PPE ('personal protective equipment'), temperature screening, etc.

\subsection{Slang Neologisms to Name the Coronavirus and the Pandemic}

Having become the key concept to be discussed in the news and private conversations, coronavirus - a word too long for the phonetic pattern of the English sentence - was soon shortened to (the) Rona in informal conversations. Another term to denote the disease, Miley Cyrus, is based on phonetic similarity and the virus' resemblance of the wrecking ball from the video by singer Miley Cyrus. There are other, quite cynical slang names such as boomer remover (due to the high death rate caused by the virus among baby-boomers) or herd thinner that emphasises the morbidity rate among patients in general.

The outbreak seems to have become a remarkable milestone, so it is now used as a temporal reference point: the abbreviation $B C$ does not only stand for before Christ but it has also come to mean before coronavirus. The scale of the ongoing pandemic is compared to biblical Armageddon and Apocalypse or the historical disaster of Holocaust. These analogies produce such blendings as Coronageddon, Coronapocalypse, and Coronacaust respectively.

Modern communication tends to drift towards combining verbal and visual components, so during the pandemic, when the most of communication flows occurred online, the degree of multimodality surged and the virus has obtained an anime representation called Corona-chan or Wuhan-chan, a young red- or green-eyed Asian woman 
with bat wings and a red dress, who is either holding a plate of bat soup or a bottle of Corona beer. The image is full of symbolic elements and may be completed with verbal messages that reveal the virus' wicked nature: the girl either threatens openly (I will suffocate your lungs), or lures into a relationship (I've always wanted to go to Madagascar. Will you take me there?). At times, the image is used in ideological struggle (then the girl is pictured with the flag of China to stress where she has come from, or says something anti-communist, e.g., 31,000 warheads couldn't kill communism. I will). The anime character also appears as part of political struggle: one of the caricatures depicts Corona-chan wearing a Trump-style wig saying The corona virus lockdown is over! Go out and throw parties to celebrate!

\subsection{Neologisms to Denote New Social Groups}

When the virus swept the United Kingdom, the British had to familiarize themselves with a new approach to categorize people. Conventional criteria such as sex, ethnicity, race, income were replaced by vulnerability or likeliness of contracting the virus. The 'COVID-resistant' majority (that was rather presupposed than nominated) was opposed to clinically extremely vulnerable people. The latter comprised of the following groups:

- aged 70 or older (regardless of medical conditions)

- under 70 with an underlying health condition listed below (that is, anyone instructed to get a flu jab each year on medical grounds):

- chronic (long-term) mild to moderate respiratory diseases, such as asthma, chronic obstructive pulmonary disease (COPD), emphysema or bronchitis

- chronic heart disease, such as heart failure

- chronic kidney disease

- chronic liver disease, such as hepatitis

- chronic neurological conditions, such as Parkinson's disease, motor neurone disease, multiple sclerosis (MS), or cerebral palsy

- diabetes

- a weakened immune system as the result of certain conditions, treatments like chemotherapy, or medicines such as steroid tablets

- being seriously overweight (a body mass index (BMI) of 40 or above)

- pregnant women (GOV.UK, 2020).

COVID-19 has also made more conspicuous social stratification and, consequently, inequality. As it turned out, likeliness to contract the virus depends not only on one's health. Another categorization, unrelated to health issues but related to professional commitment, distinguishes critical (or key) workers, i.e., those

whose work is critical to the coronavirus (COVID-19) response... This includes, but is not limited to, doctors, nurses, midwives, paramedics, social workers, care workers, and other frontline health and social care staff including volunteers; the support and specialist staff required to maintain the UK's health and social care sector; those working as part of the health and social care supply chain, including producers and distributors of medicines and medical and personal protective equipment (GOV.UK, 2020a).

The professional significance of the lower rank medical workers has been widely acknowledged and appreciated so much that 2020 has been proclaimed the Year of the Nurse:

Now more than ever, in this true Year of the Nurse and beyond, thank you and your staff members for your unwavering courage, expert care, and dedication to your patients. You're the consummate heroes on the frontlines across the globe! (Laskowski-Jones, 2020).

The virus has revealed drastic differences in living standards within society. The homeless and families in housing without running water cannot wash their hands as frequently as they are recommended, the detained are very unlikely to be able to maintain physical distancing. Certain social groups (for example, blacks, Latinos, and American Indians/Alaska Natives in the USA) are disproportionately found among the homeless, the detained, and employed in high public contact but low-benefit occupations (Van Bavel et al., 2020, p. 463). Consequently, alongside heroization of critical workers, the virus has added one more argument to the arsenal of the Black Lives Matter movement (BLM). Hence, the pandemic has lent new messages to the BLM discourse. These new slogans have been disseminated by political leaders and celebrities. American singer Beyonce's speech may be 
considered a simplified gist of the modern discourse on race in that it combines veneration of critical workers' sacrifice and statement of racial inequality that has lethal consequences:

Tonight, we celebrate true heroes, those who are making the ultimate sacrifice to keep us all safe, fair, and healthy: to the doctors, the nurses, and other health care workers who are away from their families taking care of ours. We continue to pray for their safety. To those in the food industry, delivery workers, mail carriers, and sanitation employees who are working so that we can be safe in our homes. We thank you for your selfless services. Black Americans disproportionately belong to these essential parts of the workforce that do not have the luxury of working from home, and African American communities have been severely affected in this crisis... This virus is killing black people at an alarmingly high rate here in America (Guardian News, 2020).

There are other social groups that owe their names to the outbreak. Here we find words that denote:

- generations (coronababies/corona boomers/coronials/quaranteens-generation born after December 2020 and who will become teenagers in 2033-2034)

- relationship terms (a corona boyfriend / corona girlfriend - a partner during the lockdown period that implies brevity of the relationship, a corona bud - a friend while the quarantine lasts, a bubble - a social group one is permitted to interact with while social constraints are valid, $a$ coronacrew/quaranteam - people one chooses to live with during the quarantine)

- people classified on the ground of their shopping behaviour during the pandemic (a corona chicken/coronahoarder - a person who buys toilet paper, sanitizers, etc.).

Another criterion to categorise people is their attitude to the disease. A person who brushes off the threat of the deadly virus is called covidiot/corona bro/coronasshole/coronaciser/corona clown/coronafool/coronacaust denier/morona/moronavirus. The one who is responsible and follows all the requirements and regulations of the lockdown and social distancing is a coronadult; the one who believes every nightmarish fake news about the coronavirus is a coronaddict; those who have no professional training in medicine but feel confident enough to talk about COVID-19 as if they had the expertise are armchair virologists; those who spread fake news on the disease are coronaciles; those willing to contract the virus are coronachasers.

\subsection{Neologisms to Nominate New Cultural Practices}

The fourth group of new coinages verbalises changes of everyday cultural practices. Thematically, the whole bulk of these (usually slang) neologisms may be divided into the four sets.

1) The first contains new coinages to nominate features of a new lifestyle. The main change to the routine lockdowners had to accept is formulated in the slogan \#stayhome. The restrictions on leaving one's place during the quarantine encouraged coronacocooning, i.e., wrapping oneself in the comforts of one's place and hiding from the dangerous infection. This entailed reconsidering the meaning of one's home that turned into a coronacave.

Workwise, people experienced two options: either they had to WFH (work from home) or were corona canned ('became unemployed'). Staying at home and not working was called corona holiday/coronacation (blending of corona and vacation). Coronacation blurs time perception and makes every day like any other so much that every day turns into a Blursday rather than something more specific. Blursday is not a new coinage as such, yet it used to mean 'a day spent hung over', which is certainly different from its current meaning.

On coronacation, one is engaged in a coronactivity, i.e., anything useful or useless to be done and posted on social media. Those who work from home, have their isodesk (blending of 'isolation' and 'desk', Australian English), i.e., a workplace improvised at home during the quarantimes ('quarantine' + 'times'). To make sense of the time, some people are coronabusy (or, in other words, they are coronafying): they are doing at home all those many little things that are usually done only once a year. Leisure time turns into locktail hours ('lockdown' + 'cocktail') when martini is taken out of an isobar ('isolation' + 'bar', Australian English) to make quarantinis ('quarantine' + 'martini'). The only chance to get away from the coronacave is to go on drivecation, that is, 'vacation on one's own driveway'. The period of the lockdown is marked with coronabrations when pre-planned events are Corona'd, i.e., cancelled or postponed because people are strictly prohibited from leaving their houses and gathering in groups.

The COVID-19 outbreak, especially its 'lockdown' stage, shifted most, if not all, communication online, turning into luxury face-to-face offline interactions. This transforms the reality to the extent that the Internet becomes a "lifeline" for those who lives alone (Bilefsky \& Yeginsu, 2020) as well as a window onto the world for those 
who crave for travelling (Hashim, 2020).

Pets are reconsidered as well: a coronadog is not only your close companion but also a cure for loneliness and the precious reason for breaking out of confining restrictions.

Shopping patterns have also been affected. Thus, English speakers learnt the German word hamsterkaufing to talk about panic buying or stockpiling (Evans, 2020). Fuelled by the fear that the few places and business that keep working will be coronaclosed in a while, coronahoarders buy in excess, some of them spending corona bucks/corona cash/corona checks/corona coins, i.e., money given by the state as benefit because of the COVID-19 pandemic.

2) The second set of neologisms is made up of words to nominate changes to one's appearance during the lockdown. Spending time in confinement of one's home leads to coronabesity (corona + obesity). Surplus weight is playfully called covidnineteen. Some speakers prefer to be precise and within the word specify how much weight has been gained, so one may use covidfifteen, etc. Body fat may also be referred to as corona cushion.

Taking care of one's hair is another challenge during the quarantine. Unkempt hair that needs styling is called corona coiffure/coronafro/corona hair. Some people get a coronahaircut, i.e., a haircut performed by oneself or another unqualified person from the bubble. Coronabeards appear out of boredom rather than lack of barbers or tools to shave them off, since growing a beard becomes one of the coronactivities to be shared on social media.

Socialising online enhances the status of infit, i.e., outfit worn at home. The upper part of one's outfit becomes particularly important and acquires a name of its own-upperwear, i.e., the upper part that inevitably becomes visible during videocalls and streaming sessions. People who dare to break out of the confinement of their coronacaves sometimes skip coronacouture (i.e., PPE), yet they have to coronafy ('to gear up with gloves and a mask') or to put on a corona face (that is, a mask and sunglasses).

3) The third set contains neologisms to refer to customs, i.e., everyday ritual behaviours. The etiquette of face-to-face communication has been severely affected by new rules that impose restrictions on any tactile expression of affection. Since hands and a face were declared the most 'dangerous', 'virus-sensitive' and 'virus-spreading' parts of the body, the first 'affection symbols' that fell victim to social distancing were handshake and kissing. Meetings of people from different households were accompanied by new gestures that helped coronadults express their warm feelings as well as reduce the physical contact. The pre-pandemic non-verbal synonyms to a greeting kiss or handshake are waving or nodding, so they persisted. Some of the 'safe substitutes' for kissing and handshaking cannot be called innovations but are rather 'cultural borrowings' (for example, the Thai 'wai'/Indian 'namaste' have come from other ethnic cultures, while a fist bump is a greeting popular in boxing subculture). These non-verbal messages did not receive any new names in English.

However, there have been inventions, i.e., new body movements that equal a handshake. One of them is a Wuhan shake, also known as Wuhan five and corona five which consists of tapping one's foot against the other person's foot. It started in China and went viral on social media (Ritschel, 2020). Another new greeting gesture is called elbow bump (or, when shortened, elbump) and means briefly touching somebody's elbow with one's own.

4) Neologisms to name interpersonal relations and computer-mediated interactions make up the fourth set. The disease and the quarantine divide people into two categories: one's family and the rest of the world. One's family is a relatively safe circle but being stuck indoors with them for two months in a row may feel like psychological trial. Some marriages failed to withstand the lockdown test and ended in a covidivorce.

Single people had to taste the difference between being alone and being lonely. At the time when meeting new people could mean contracting the lethal disease, any relationship is dangerous, yet some singles preferred to find somebody to be with and start a coronarelationship ('a temporary relationship with somebody one knows maintained because one does not want to stay alone during the quarantine'). As a rule, the initial stage presupposed coronadating/coronacourting/quarandating (that is, maintaining a romantic relationship via the phone, video chat, actual dates when the couple get no closer than six feet apart) and only then some courageous lovers ventured into intimate relations.

Another aspect of any romantic relationship is breaking up. Involved in a computer-mediated love affair, one may be zumped (a blend of 'Zoom' and 'dump' that means being abandoned in a videoconference) by a partner. In should be noted, that bosses may also zump (i.e., fire) their employees, once all communication is online.

Computer-mediated relations with friends are held with the help of videoparties/covideo parties/zoom parties where one spends happy hours with quarantinis. Homeferences of more formal nature (for example, work-related) are held with much attention paid to upperwear and require virtual backgrounding/refurbishing, i.e., careful preparation of the interior that will be seen by the partner at the other computer. It is noteworthy that 
Internet users whose online life is particularly intense tend to arrange a Zoom room in their houses with a permanently appropriate background. The online format of interactions leads to zoom fatigue: one gets zoomed out (exhausted after spending much time in videoconference).

\section{Discussion}

In this paper, we have considered the neologisms coined to verbalise the new reality of the coronavirus pandemic. The analysis sheds light not only on the meanings of the new words and their word-building patterns but also on the cultural processes that have been taking place starting from January, 2020.

The material reveals that there are three applicable approaches to Coronaspeak neologisms: stylistic, etymological, and denotational. The stylistic neologisms emerged when medical terms ceased to be used by medical professionals and became common in everyday conversations. The etymological neologisms within Coronaspeak are scientific terms that show semantic changes. The denotational neologisms make up the most numerous group and name new concepts that appeared during the pandemic. It should be noted that most of the denotational new coinages are blendings, which means they denote 'something old that undergone changes in new conditions'. The first component of the blendings as a rule points out the 'conditions' (corona-, covid-, quaran-), while the second component names the concept itself (activity, hoarder, dating).

The changes on the lexical level are related to discourse transformations and, finally, culture. First of all, constant exposure to information on the virus, on COVID-19 symptoms, and drills into the quarantine rules have brought about medicalisation of the average citizen's discourse: medical terms are migrating from specialised vocabulary to the layer of common words and becoming stylistic neologisms.

Secondly, it is peculiar that the virus has acquired many colloquial names though the initial medical term coronavirus was quickly assimilated by the public. The abundance of nominations enables us to argue that the virus has indeed been central in everyday discourse. It is also noteworthy that the coronavirus has become the first disease to acquire its anthropomorphic, easily recognisable visual image. The image has been turned into a weapon in political struggle in order to deepen ideological and/or cultural divide: the virus was used in the 'China vs USA' confrontation as well as in 'Trump vs Democrats' argument.

In addition, the pandemic has influenced people's time perception where it has become an important reference point, a milestone, a dramatic event that divides life into 'before' and 'after'. It is this conceptualisation that is implied in the blendings Coronageddon and Coronacaust. The idea of historical significance attributed to the pandemic underlies neologisms coronials, quaranteens coined to refer to a generation: the coronavirus has impacted on people just like Apple gadgets that produced the iGeneration a little earlier.

The shift to medicalised discourse has brought about new social categories. The present-day government discourse is focused on clinically vulnerable people and key workers. Some representatives of the latter group, e.g., sanitary engineers and nurses, used to receive very little attention from the public, yet the new reality has brought them admiration and glory: they have become true heroes working on the frontline. Thus, the use of new coinages in discourse reveals changes in social hierarchy and the groups' perceived social value. Since many key workers belong to racial minorities, their newly acquired significance combines with other, pre-existing social and cultural factors and escalates tension within the society.

The new vocabulary contains antonyms that denote different attitudes to the quarantine rules: there are responsible coronadults, who comply with all the restrictions, and covidiots, who flout the rules and risk their own lives as well as others'. These also presuppose social categorisation that arose in the new reality.

Besides the large-scale changes, the neologisms reveal that the coronavirus epidemic has impacted on everyday culture in a number of ways: people have to review their lifestyle and customary 'way of doing things', e.g., working, shopping, one's appearance, and relationships. Switching to a new lifestyle is not easy, so citizens try to modify their habits to adapt them to new rules. This is how blendings drivecation and videoparties appear. The most basic concepts, such as home, dog, and Internet, have acquired new significance and connotations. On the one hand, home is seen as the only safe place (coronacave) but, on the other hand, it is a place of confinement. It also becomes a workplace, which entails development of a new etiquette peculiar to coronaculture. This includes arranging one's space and one's appearance so that it may be appropriate to perform one's functions at work while staying at home. This is what Zoom room, virtual refurbishing, and upperwear verbalise. Even loosening of the lockdown restrictions does not cancel social distancing, which leads to the development of new greeting rituals in face-to-face encounters, such as Wuhan shake and elbump.

New coinages include terms that conceptualise new types of relations. Quaranteam used to refer to one's family implies warmth and cooperation that bound family members during the lockdown ordeal. There is also a new 
type of temporary relations (coronarelationship) maintained while the lockdown lasts and a new type of divorce (covidivorce) filed for because a couple could not bear to spend with each other all the time during the quarantine.

\section{Conclusions}

Drawing on the assumption of the language-culture correlation, the study views neologisms coined during the 2020 coronavirus pandemic and making up Coronaspeak as a shortcut to cultural changes.

The three theories of neologisms are relevant to Coronaspeak, namely stylistic, etymological, and denotational. Stylistic neologisms used to be medical terms but in 2020 have moved into everyday discourse; etymological neologisms have changed their meaning though preserved their form; denotational neologisms emerged to name new phenomena.

The analysis of the new coinages has given an insight into novel cultural practices (i.e., coronaculture) that include centrality of the coronavirus in the public discourse in particular and medical issues in general, perception of the pandemic as a reference point of historic significance, emergence of new social groups, reconceptualisation of old notions, and development of new communication practices.

\section{References}

Bilefsky, D., \& Yeginsu, C. (2020, March 27). Of 'Covidivorces' and 'Coronababies': Life During a Lockdown. New York Times. Retrieved from https://www.nytimes.com/2020/03/27/world/coronavirus-lockdown-relationships.html

Blommaert, J. (2020, March 6). COVID 19 and globalization [Blog post]. Retrieved from https://alternative-democracy-research.org/

Chaiuk, T. A., \& Dunaievska, O. V. (2020). Producing the Fear Culture in Media: An Examination on Coronavirus Discourse. Journal of History Culture and Art Research, 9(2), 184-194. https://doi.org/10.7596/taksad.v9i2.2636

Dunaievska, O. V., \& Chaiuk, T. A. (2020). Modifying "Breaking Bad News" Communication: Cross-Cultural and Cognitive-Semantic Approaches. Academic Journal of Interdisciplinary Studies, 9(2), 1-14. https://doi.org/10.36941/ajis-2020-0017

Dupont, K. (2020, May 12). Do you speak Covid? Heidi.news. Retrieved from https://www.heidi.news/geneva-solutions/covid-slang-let-s-check-if-you-re-up-to-coronapace

Evans, S. (2020, July 6). Diary of an Optimist: 'Hamsterkaufing' hits the shelves. The Canberra Times. Retrieved from

https://www.canberratimes.com.au/story/6816145/diary-of-an-optimist-hamsterkaufing-hits-the-shelves/

Farese, G. M. (2018). The Cultural Semantics of Address Practices: A contrastive study between English and Italian. Lanham: Lexington Books.

Figus, A. (2020). Coronavirus COVID-19, a complex issue between health, economy, politics, and communication. Geopolitical, Social Security and Freedom Journal, 3(1). https://doi.org/10.2478/gssfj-2020-0001

Goldberg, M. H., Gustafson, A., Maibach, E. W., van der Linden, S., Ballew, M. T., Bergquist, ... Leiserowitz, A. (2020, May 4). Social Norms and COVID-19 Preventive Behaviors. Working paper. https://doi.org/10.31234/osf.io/9whp4

GOV.UK. (2020a, June 16). Critical workers who can access schools or other educational settings. Retrieved July 16, 2020, from https://www.gov.uk/government/publications/coronavirus-covid-19-maintaining-educational-provision/guid ance-for-schools-colleges-and-local-authorities-on-maintaining-educational-provision\#critical-workers

GOV.UK. (2020b, July 14). Guidance on shielding and protecting people who are clinically extremely vulnerable from COVID-19. $\quad$ Retrieved from https://www.gov.uk/government/publications/guidance-on-shielding-and-protecting-extremely-vulnerable-p ersons-from-covid-19/guidance-on-shielding-and-protecting-extremely-vulnerable-persons-from-covid-19

Guardian News. (2020, April 19). Beyonce: coronavirus is 'killing black people at an alarming rate in America' [Video file]. Retrieved from https://www.youtube.com/watch?v=9WBDnumqBT0

Ha, J. F., Anat, D. S., \& Longnecker, N. (2010). Doctor-Patient Communication: A Review. The Ochsner Journal, 
$10(1), 38-43$.

Harrod, M., Leonard, S., \& Negra, D. (2020). Romance in the Time of Coronavirus. Retrieved from https://www.academia.edu/43429222/Romance_in_the_Time_of_Coronavirus

Hashim, R. S. (2020). View from My Window: Global Connections during COVID-19. 3L: The Southeast Asian Journal of English Language Studies, 26(2), 10-13. https://doi.org/10.17576/3L-2020-2602-01

Huang, J. (2020, March 13). Chinese Diplomat Accuses US of Spreading Coronavirus. Voice of America. Retrieved

from https://www.voanews.com/science-health/coronavirus-outbreak/chinese-diplomat-accuses-us-spreading-cor onavirus

Jarus, O. (2020, March 20). 20 of the worst epidemics and pandemics in history. Live Science. Retrieved from https://www.livescience.com/worst-epidemics-and-pandemics-in-history.html

Kim, H. T., Woods, P., Azman, H., Abdullah, I. H., Hashim, R. S., Rahim, ... Kosem, I. COVID-19 Insights and Linguistic Methods. 3L: The Southeast Asian Journal of English Language Studies, 26(2), 1-23. https://doi.org/10.17576/3L-2020-2602-01

King's College of London. (2020, April 16). \#CORONASPEAK - the language of Covid-19 goes viral. Retrieved from https://www.kcl.ac.uk/news/coronaspeak-the-language-of-covid-19-goes-viral

Koltsova, E. A. (2017). Neologisms in the English Language in the 21st century. RUDN Journal of Language Studies, Semiotics and Semantics, 8(3), 604-613. https://doi.org/10.22363/2313-2299-2017-8-3-604-613

Laskowski-Jones, L. (2020). COVID-19 and changing social norms. Nursing, 50(5), 6. https://doi.org/10.1097/01.NURSE.0000659348.89357.ac

Levisen, C., \& Waters, S. (2018). Cultural Keywords in Discourse. Amsterdam: John Benjamins. https://doi.org/10.1075/pbns.277

Li, Y. (2020, March 27). Language lessons of COVID-19 and linguistic disaster preparedness. Language on the Move. Retrieved

from https://www.languageonthemove.com/language-lessons-of-covid-19-and-linguistic-disaster-preparedness/

Murphy, C., Naert, S., \& Strong, C. (2020). Coronavirus \& Behaviour Change: What does it mean for brands? Ipsos. Retrieved from https://www.ipsos.com/sites/default/files/ct/publication/documents/2020-04/ipsos-coronavirus-behavior-cha nge.pdf

NHS. (2020). Self-isolation and treating coronavirus symptoms. Retrieved from https://www.nhs.uk/conditions/coronavirus-covid-19/self-isolation-and-treatment/

Oxford Languages. (2019). Word of the Year 2019. Retrieved from https://languages.oup.com/word-of-the-year/2019/

Oxford Owl. (2020, June 10). Oxford Children's Word of the Year: Coronavirus [Blog post]. Retrieved from https://home.oxfordowl.co.uk/blog/2020-oxford-childrens-word-of-the-year-coronavirus/

Peeters, B., \& Marini, M. G. (2018). Narrative Medicine across languages and cultures: Using Minimal English for increased comparability of patients' narratives. In C. Goddard (Ed.), Minimal English for a global world: Improved communication using fewer words (pp. 259-286). London: Palgrave Macmillan. https://doi.org/10.1007/978-3-319-62512-6_11

Rets, I. (2016). Teaching Neologisms in English as a Foreign Language Classroom. Procedia: Social and Behavioural Sciences, 232, 813-820. https://doi.org/10.1016/j.sbspro.2016.10.110

Ritschel, C. (2020, March 2). Wuhan shake: People in China developing new ways to greet each other amid coronavirus fears. Independent. Retrieved from https://www.independent.co.uk/life-style/wuhan-shake-china-coronavirus-hand-greeting-spread-virus-a9370 996.html

Singh, M., Davidson, H., \& Borger, J. (2020, May 1). Trump claims to have evidence coronavirus started in Chinese lab but offers no details. The Guardian. Retrieved from https://www.theguardian.com/us-news/2020/apr/30/donald-trump-coronavirus-chinese-lab-claim

Song, S. (2020, May 2). New social norms emerge in the age of COVID-19. The Korea Herald. Retrieved from http://www.koreaherald.com/view.php?ud=20200429000273 
Szabó, R. (2020). No Going Back: The Impact of the COVID-19 Pandemic on Corporate Language and Communication Training. Journal of Humanities and Social Sciences Research, 2(S), 23-30. https://doi.org/10.37534/bp.jhssr.2020.v2.nS.id1032.p23

Thibodeau, P. H., \& Boroditsky, L. (2013). Natural Language Metaphors Covertly Influence Reasoning. PLoS ONE, 8(1), e52961. https://doi.org/10.1371/journal.pone.0052961

Thorne, T. (2020, June 1). Spotlight on COVID: Pandemic language and the role of linguistics. King's College London. News Centre. Retrieved from https://www.kcl.ac.uk/news/spotlight-on-covid-pandemic-language-and-the-role-of-linguists-1

Urban Dictionary. (n.d.). In Wikipedia. Retrieved July 7, 2020, from https://en.wikipedia.org/wiki/Urban_Dictionary\#Quality_control

Van Bavel, J. J., Baicker, K., Boggio, P. S., Capraro, V., Cichocka, A. ..., Willer, R. (2020). Using social and behavioural science nto support COVID-19 pandemic response. Nature Human Behaviour, 4, 460-471. https://doi.org/10.1038/s41562-020-0884-z

Wierzbicka, A. (1988). The Semantics of Grammar. Amsterdam: John Benjamins. https://doi.org/10.1075/slcs.18

World Health Organization. (2020). WHO Timeline-COVID-19. Retrieved from https://www.who.int/news-room/detail/27-04-2020-who-timeline---covid-19

Ye, Z. D. (2004). Chinese categorization of interpersonal relationship and the cultural logic of Chinese social interaction: An indigenous perspective. Intercultural Pragmatics, 1(2), 211-230. https://doi.org/10.1515/iprg.2004.1.2.211

Yoon, K.-J. (2004). Not just words: Korean social models and the use of honorifics. Inter-Cultural Pragmatics, 1(2), 189-210. https://doi.org/10.1515/iprg.2004.1.2.189

\section{Copyrights}

Copyright for this article is retained by the author, with first publication rights granted to the journal.

This is an open-access article distributed under the terms and conditions of the Creative Commons Attribution license (http://creativecommons.org/licenses/by/4.0/). 